\section{Progress and challenges to the global waste management system}

\author{
Jagdeep Singh, Rafael Laurenti, Rajib Sinha and Björn Frostell
}

Waste Management \& Research

2014, Vol. 32(9) 800-812

(c) The Author(s) 2014

Reprints and permissions:

sagepub.co.uk/journalsPermissions.nav DOI: 10.1177/0734242X14537868

wmr.sagepub.com

@SAGE

\begin{abstract}
Rapid economic growth, urbanization and increasing population have caused (materially intensive) resource consumption to increase, and consequently the release of large amounts of waste to the environment. From a global perspective, current waste and resource management lacks a holistic approach covering the whole chain of product design, raw material extraction, production, consumption, recycling and waste management. In this article, progress and different sustainability challenges facing the global waste management system are presented and discussed. The study leads to the conclusion that the current, rather isolated efforts, in different systems for waste management, waste reduction and resource management are indeed not sufficient in a long term sustainability perspective. In the future, to manage resources and wastes sustainably, waste management requires a more systems-oriented approach that addresses the root causes for the problems. A specific issue to address is the development of improved feedback information (statistics) on how waste generation is linked to consumption.
\end{abstract}

\title{
Keywords
}

Global challenges, resource management, root causes, systems approach, wastes

\section{Introduction}

In the last few decades, rapid economic development and urbanization have resulted in substantial improvements in well-being for large fractions of the world population. At the same time, we have seen increased materially intensive resource consumption and consequently the release of large amounts of waste to the environment (Blanchard, 1992; Gerbens-Leenes et al., 2010; Wenheng and Shuwen, 2008). Bylinsky (1995) reports that according to the American National Academy of Sciences, 94\% of the substances that are pulled out of the earth enter the waste stream within months.

Waste is regarded as by-products or end products of the production and consumption process, respectively (European Union, 2008). In the current linear model of resource consumption, resources entering into the human environment are processed, transformed, used and discarded to nature in the form of solid, liquid and gaseous wastes. 'Production' and 'consumption' are very broad terms and can encompass many human activities, such as agriculture, construction and demolition, industrial and so on. Within the scope of this article, the discussion is limited to the industrial activities only.

During the last few decades, resource/waste management has been developing operationally and technologically in response to resolve contemporary environmental, technical and economic challenges. However, current global waste management (WM) practices focus on reducing the impacts rather than preventing them, and suggest, so called, 'end of pipe' solutions to waste problems rather than long term sustainable measures (Seadon, 2010).
Several initiatives, such as cleaner production, design for environment, extended producer responsibility (EPR) and industrial symbiosis, were introduced in production and consumption systems (Frosch and Gallopoulos, 1989; Lifset, 1993; OECD, 2006). Such technological and operational innovations have broadened the discussion on waste issues to achieve the required resource efficiency, yet they focus on the individual product or systems in isolation rather than on a more coherent systems approach.

An integrated approach to WM requires the accounting and control of all kinds of emissions (gaseous) and wastes (solid and liquid) (Stiles, 1996). Therefore, a broad possible definition of integrated WM system could be given as 'a process of change, in which the concept of WM is gradually broadened to eventually include the necessary control of gaseous, liquid and solid material flows in the human environment, emphasizing precautionary actions' (Anonymous, 1991). This multi-media approach, which considers the gaseous, liquid and solid emissions, enables a more holistic picture to become evident, and encourages reflection on upstream processes with a view to emissions reduction (Stiles, 1996).

Division of Industrial Ecology, KTH Royal Institute of Technology, Stockholm, Sweden

\section{Corresponding author:}

Jagdeep Singh, Division of Industrial Ecology, Teknikringen 34, KTH Royal Institute of Technology, Stockholm 10044, Sweden.

Email: jagdeeplakth.se 


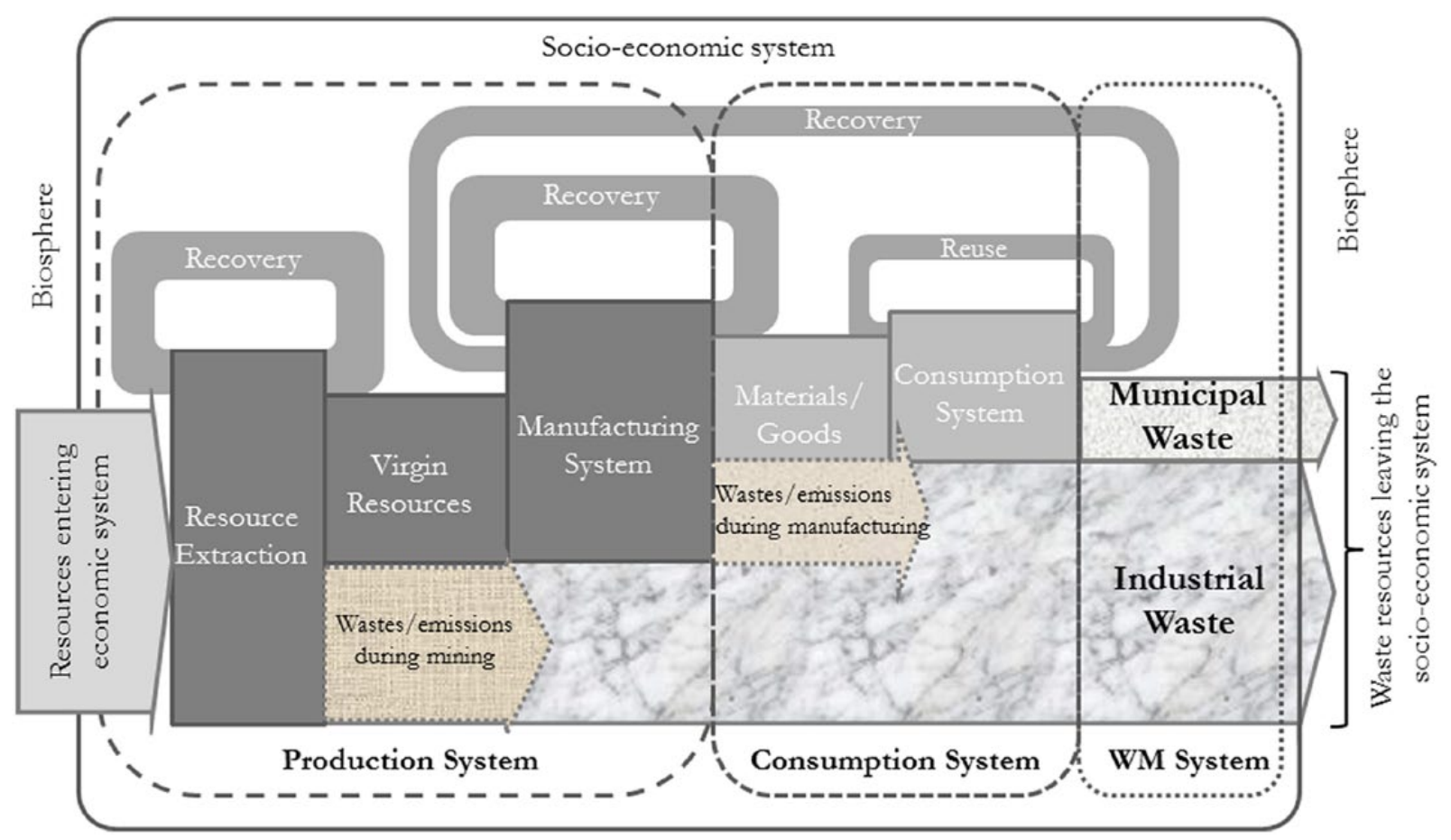

Figure 1. Wastes in our Society - liquid, gaseous and solid emissions/wastes - generation during the extraction, production, consumption and final disposal phases. Household waste refers to municipal solid waste generated during household consumption processes; and industrial wastes are the collective wastes generation from production activities (resource extraction and manufacturing).

WM: waste management.

Waste issues have been recognized as a global rather than local environmental problem, because of the significant contribution of waste-related emissions to, for example, climate change. Indeed, waste-related greenhouse gas (GHG) emissions are estimated to be $5 \%$ of the total GHG emissions and are expected to increase to $9 \%$ in 2020 with business as usual (UNEP, 2011; UNFCCC, 2005). This calls for an environmentally sound approach to WM that must go beyond the mere safe disposal, or recovery, of wastes that are generated and seek to address the root causes of the problem by attempting to change unsustainable patterns of production and consumption (UN, 1993).

In this article, progress and key challenges faced by current resource management in a global perspective are discussed in order to study current status of the global resource management system. Need for a broader systems approach to resource management is emphasized, where waste issues are discussed together with production and consumption. The article is outlined according to the following: 'Wastes in our society: sources, generation and composition'; 'Progress in waste management'; 'Challenges to the global resource management system'; 'Need for a broader systems approach to resource management'; and finally 'Conclusion and discussions'.

\section{Wastes in our society: sources, generation and composition}

Waste generation is inevitable during the production and consumption of resources owing to the first and second law of thermodynamics. The production and consumption of intended goods gives rise to additional unintended outputs, such as tailings from mining processes and wastes from industrial processes; wastes owing to the use of energy and materials during the use-phase of the products; and gaseous emissions owing to the collection and treatment processes, which may be unintended and even harmful to the environment (Kronenberg and Winkler, 2009). Thus, from a life-cycle perspective, production of unintended gaseous, liquid and solid byproducts or end-products takes place during the extraction, production, consumption and final treatment of the resources (Figure 1). Table 1 indicates the estimated amounts of wastes generated from different sources - extraction, production and consumption. Indeed, the wastes from mining and production activities are much higher in mass as compared with wastes leaving the consumption system, for example in the form of discarded products. Within the scope of this article, resource/waste flows during the production (resource extraction and product manufacturing) and consumption (product use and discard) activities are discussed in detail.

\section{Industrial wastes}

Industrial waste generation and composition depends upon various factors, such as the degree of industrialization and type of industrial setup in the country. Mining activities to supply raw materials for energy generation and goods manufacturing produce tremendous amounts of wastes, often non-hazardous (Table 1). Therefore, ecological damage owing to the rucksack and release of these wastes into nature cannot be underestimated. Comparatively, industries emit more concentrated pollutants and in bigger amounts on per-source basis (Chalmin and Gaillochet, 2009). Therefore, 
Table 1. Estimated global waste generation and collection in the year 2006 (in billion tonnes). Adapted from Chalmin and Gaillochet (2009).

\begin{tabular}{lll}
\hline Waste (in billion tonne) & Generated & Collected \\
\hline $\begin{array}{l}\text { Mining, electricity and water industry } \\
\text { (non-hazardous)a }\end{array}$ & 6.4 & n.d. \\
Manufacturing industry (non-hazardous) & 1.2 to 1.67 & 1.2 \\
Manufacturing industry (hazardous) & 0.490 & 0.3 \\
World total municipal solid waste & 1.7 to 1.9 & 1.24 \\
\hline
\end{tabular}

n.d.: no data available.

aWaste produced in a selection of countries. For more information see: Chalmin and Gaillochet C (2009).

Source: Chalmin and Gaillochet (2009).

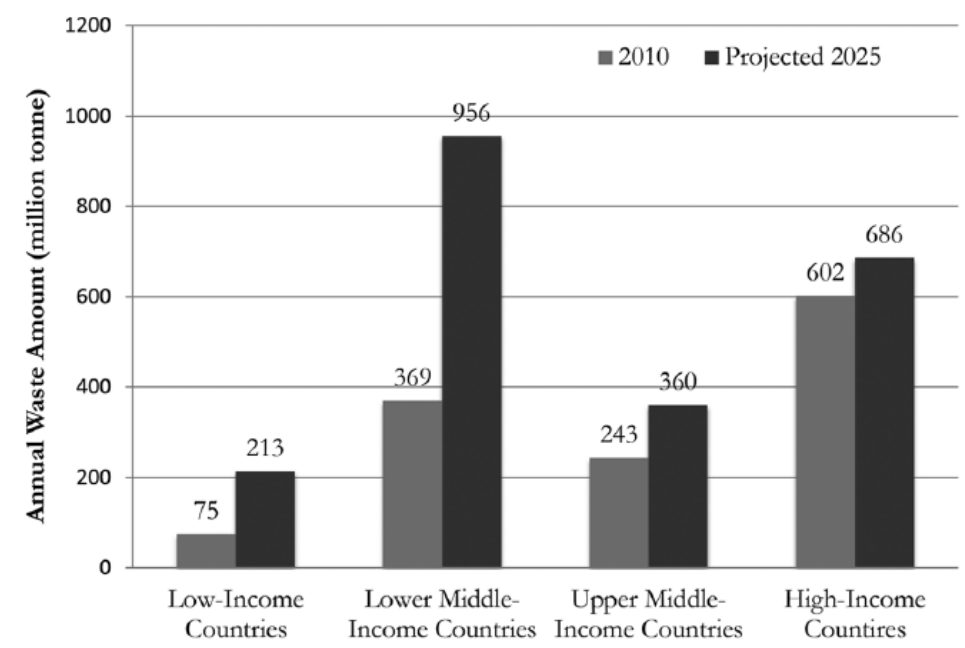

\begin{tabular}{|c|c|c|c|c|c|c|c|c|}
\hline & 2010 & 2025 & 2010 & 2025 & 2010 & 2025 & 2010 & 2025 \\
\hline $\begin{array}{c}\text { Urban Population } \\
\text { (millions) }\end{array}$ & 343 & 676 & 1296 & 2080 & 572 & 619 & 774 & 912 \\
\hline $\begin{array}{c}\text { Waste } \\
\text { (kg/capita/day) }\end{array}$ & 0.6 & 0.86 & 0.78 & 1.3 & 1.16 & 1.6 & 2.13 & 2.1 \\
\hline
\end{tabular}

Figure 2. Estimated annual MSW generation in the year 2010 and 2025 in different countries based on economic development and urban population. Classification of the countries is based on the World Bank classification based on per-capita income levels.

The values for the year 2010 are the current estimated values based on the data collected and assumed for major cities in the countries and the values for the year 2025 are extrapolated with appropriate assumptions regarding, for example, economic growth and waste generation rates. For more information see: World Bank (2012).

Data sources: The World Bank (2012).

they are relatively easier to manage since their composition and characteristics are usually known at the factory site.

Industrial waste generation rates are largely unknown owing to incomplete, heterogeneous and uncertain available data (Chalmin and Gaillochet, 2009; World Bank, 2012), thus could be ascribed to the fact that in many countries, the industrial wastes are managed by the municipalities, thus they are regarded as part of WM streams. In some countries, industrial waste includes waste generated by the production of energy, and even mining waste (Chalmin and Gaillochet, 2009).

\section{Municipal solid waste (MSW)}

MSW generation is affected by different factors, such as population; socioeconomic development index (HDI) and the income level (GNI per capita) (Wilson, 2007; Wilson et al., 2012b); and climate of the region (World Bank, 2012). Generally, the greater the economic prosperity, the greater the amount of waste produced. Figure 2 shows the urban MSW amounts in low- middleand high-income countries. (Classification of the countries is based on income levels: Low-income countries ( $<$ US\$876), middle-income countries (lower-middle and upper-middle income countries are combined together for comparison purposes) (US\$876 to $\leq \mathrm{US} \$ 10,725)$, high-income countries (>US\$10,725).) Rapidly growing MSW amounts in the lowand middle-income countries can be ascribed to the fast economic development and increasing population and urbanization in these countries. In high-income countries, the MSW growth has stabilized; however, waste amounts are still increasing but at a very low rate. Indeed, in these countries, per capita waste (kg/capita/day) generated is already very high as compared with low- and middle-income countries (see Figure 2). 


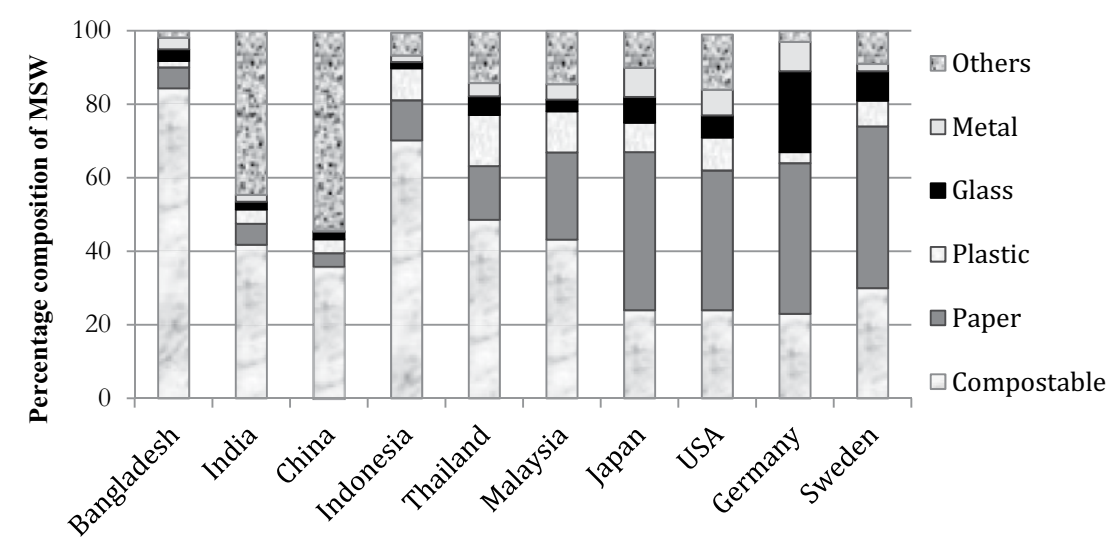

Figure 3. Percentage composition of the key components (organics, paper, plastic, glass, metal and others) of MSW in different countries.

The composition values are assumed to be based on wet weight. The share of the 'others' component is very high for countries such as India and China. This could be owing to high amounts of sand and grit being swept and/or to methodological problems in the definition of various components of waste streams. For more information and discussion on waste composition and the reliability of the data, please see Wilson et al. (2012b).

Data sources: The World Bank (2012), OECD (2000) and ESCAP (2000).

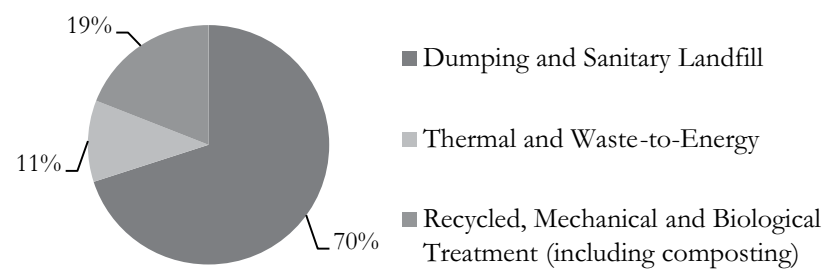

Figure 4. Status of global MSW management. Out of the total annual amount of waste generated worldwide in 2006 (municipal, industrial and hazardous), MSW was 1.7-1.9 billion tonnes and most it was driven to dumpsites and sanitary landfills worldwide.

Data source: Chalmin and Gaillochet (2009).

Similar to MSW quantities, their compositions also show a 'strong' relationship with economic development (see Figure 3). Indeed, the waste compositions vary not only between countries, but also between individual cities and communities within a city, depending upon the economic situation of the particular community (World Bank, 2012). The waste composition impacts the collection and disposal of the waste. Indeed, for the last few decades, the growing complexity of waste streams, such as e-wastes, has been presenting new challenges to WM operations.

Figure 4 shows the estimated share of various waste treatment options for global MSW in 2006. Out of the total waste generated (municipal, industrial and hazardous) $70 \%$ was lanfilled (total waste managed by open dumps and engineered or sanitary landfills, which was not available for recycling in the socio-economic systems). From a long-term sustainability perspective, this presents a great challenge to future resource security.

\section{Progress in waste management}

\section{Development drivers for progress in WM}

WM activities around the world have improved continuously in several aspects, such as operational, technological and institutional, thanks to different contemporary drivers. Wilson (2007) identifies various drivers for the progress in WM, such as the need for: (1) improved public health, (2) improved environment protection, (3) improved resource efficiency, (4) combating climate change, (5) improved institutional capacity and (6) increased public awareness and participation. Owing to emerging discussions on sustainability issues in the 1990s, waste-related issues were increasingly recognized as a global sustainability challenge, rather than a local environmental problem. Consequently, over the last two decades, WM has evolved with relatively broader aims, including production and consumption (Geng et al., 2010; Munir et al., 2012) (see Figure 5 presented later in this article) to manage waste by creatively minimizing its environmental impacts using technological approaches (especially in high-income countries). This has introduced a wide array of eco-innovations (European Union, 2006) in the premises of product design, consumers, product-service and governance (Carrillo-Hermosilla et al., 2010) to develop prevention-oriented approaches to solve waste issues. Consolidation of environmental information exchange within the design process, production and WM systems has been increased. The focus has been shifted from 'end-of-pipe' practices to systems-oriented resource management by preventing waste generation and sustainable treatment of waste resources.

\section{Progress in waste minimization and treatment}

Waste minimization encompasses three elements in priority: preventing and/or reducing the generation of waste at source; improving the quality of the waste generated, such as reducing the hazard; and encouraging re-use, recycling and recovery (EEA, 2002; OECD, 1998). Therefore, waste minimization is a broad term that involves waste prevention as well as treatment measures (EEA, 2002). Waste prevention means taking measures that reduce: (a) the quantity of waste, including through the 

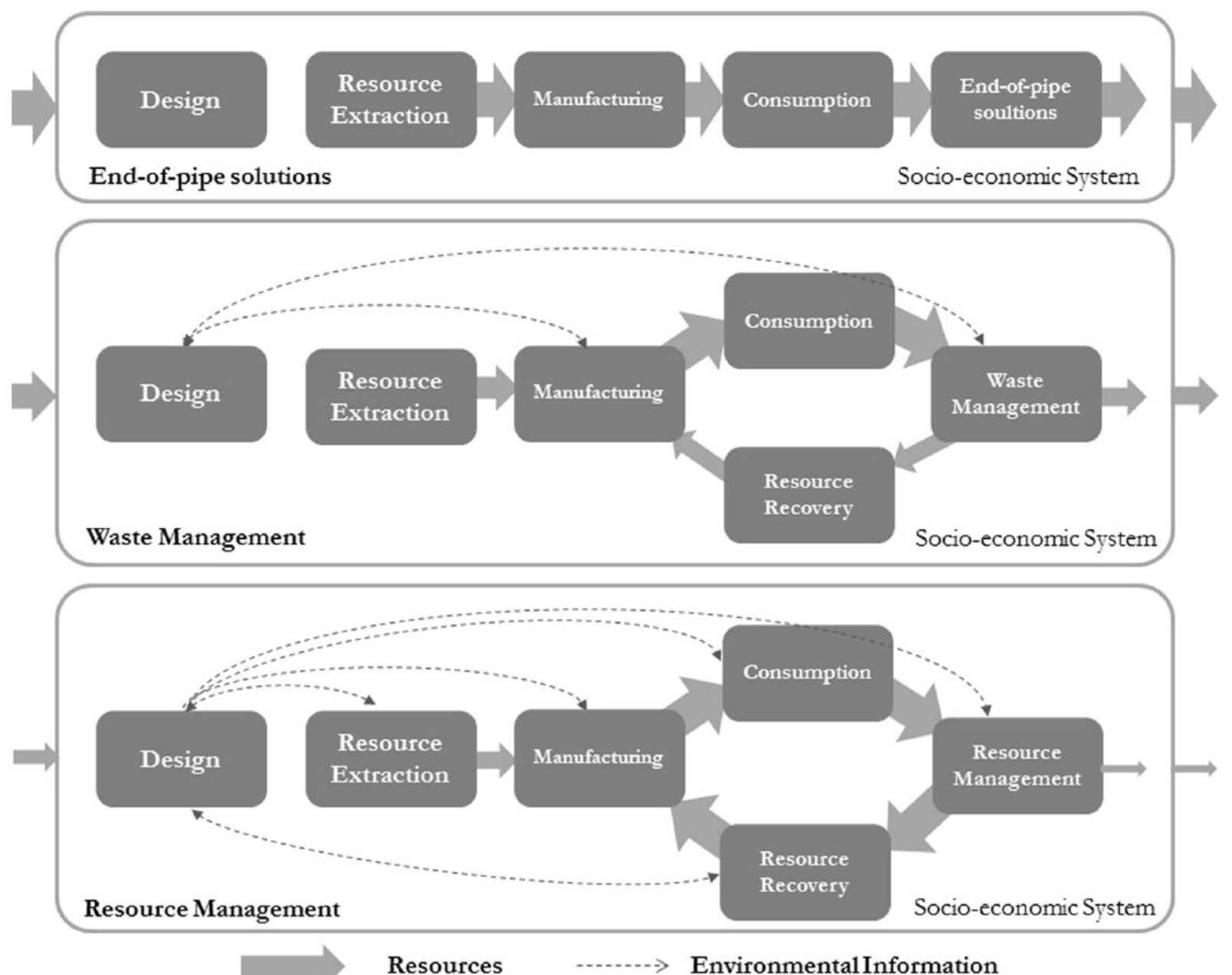

Figure 5. Developments in resource management - from 'end-of-pipe' approaches to more systems-oriented approaches. Thick arrows qualitatively show the material flows through the system and dotted arrows show the environmental information exchange among various socio-technical systems. Environmental information refers to the information exchange among various socio-economic subsystems to deliver environmental goals.

re-use of products or the extension of the life span of products; (b) the adverse impacts of the generated waste on the environment and human health; or (c) the content of harmful substances in materials and products (European Union, 2008; European Union, 2012). The measurement of prevention is very challenging; nonetheless, studies (Fell et al., 2010; Gottberg et al., 2010; Sharp et al., 2010; Wilson et al., 2012a; Wilts, 2012; Zorpas and Lasaridi, 2013) have shown potentially huge benefits of waste prevention for businesses.

Following these definitions, waste minimization and prevention measures in different socio-technical sub-systems production, consumption and WM - can be summarized as shown in Table 2. The operational, technological and institutional progress to address waste issues can be divided into two parts: initial 'end-of-pipe' progress between the 1960s and 1980s; and the recent more systems-oriented progress (as illustrated in Figure 5).

Initial progress to WM. Initially, the main drivers for the developments in WM were contemporary local environmental implications, such as pollution and local water body contamination caused by local dump sites (Wilson et al., 2012b). Until the 1960s, WM was limited to merely removing waste before it became a health hazard to a local population (Wilson, 2007).

In the 1960s and 1970s, the waste disposal issues were brought onto the political agenda, owing to the environmental movements in the industrialized countries and consequent legal enforcements. Nonetheless, the waste issues were considered to be a local environmental problem and largely as a technological problem with engineering solutions. With increasing waste amounts and related environmental concerns with open dumping and open burning of the waste, the initially adopted steps were to ban such practices and to develop separate landfill sites as 'end-of-pipe' solutions to waste problems.

In the 1980 s, owing to increasing energy costs, waste-toenergy technologies were proven economically feasible, leading to rapid commercialization of waste-to-energy technologies in high-income countries (Nakaiwa et al., 1986; Rylander, 1985; Sternlicht, 1982). This development helped municipalities to divert a significant portion of waste from landfills. At the same time, it offered benefits such as recovered energy and saved 
Table 2. Waste prevention and treatment measures in different socio-economic sub-systems.

\begin{tabular}{|c|c|c|c|c|}
\hline \multicolumn{2}{|c|}{ Waste minimization concepts } & \multicolumn{3}{|l|}{ Approaches/measures } \\
\hline & & Production system & Consumption system & $\begin{array}{l}\text { Waste management } \\
\text { system }\end{array}$ \\
\hline $\begin{array}{l}\text { Prevention } \\
\text { measures }\end{array}$ & $\begin{array}{l}\checkmark \text { Reducing the quantity } \\
\text { of waste } \\
\checkmark \text { Reduction of adverse } \\
\text { impacts of generated } \\
\text { waste } \\
\checkmark \text { Reducing the content of } \\
\text { harmful substances in } \\
\text { material and products }\end{array}$ & $\begin{array}{l}\text { - Resource efficiency } \\
\text { - Extending product's life- } \\
\text { span } \\
\text { - Cleaner production } \\
\text { - Design for environment }\end{array}$ & $\begin{array}{l}\text { - } \text { Re-use and repair of } \\
\text { products } \\
\text { - Sorting of waste (e.g. } \\
\text { separating organic } \\
\text { recyclable wastel }\end{array}$ & $\begin{array}{l}\text { Diverting waste } \\
\text { from landfills }\end{array}$ \\
\hline $\begin{array}{l}\text { Treatment } \\
\text { measures }\end{array}$ & $\begin{array}{l}\checkmark \text { Reduction at source } \\
\checkmark \text { Re-use of products } \\
\checkmark \text { Quality improvement } \\
\checkmark \text { Recycling }\end{array}$ & $\begin{array}{l}\text { - Industrial symbiosis, eco- } \\
\text { industrial park } \\
\text { - Taking responsibility } \\
\text { for generated wastes, e.g. } \\
\text { through EPR programmes } \\
\text { - Remanufacturing, re- } \\
\text { assembly }\end{array}$ & - Product 'take-back' & $\begin{array}{l}\text { - Recycling } \\
\text { - Energy recovery } \\
\text { - Pre-treatment } \\
\text { of wastes before } \\
\text { disposal }\end{array}$ \\
\hline
\end{tabular}

landfill area. However, these developments have lacked a broad systems perspective on managing wastes; they focused on the same principal of 'dilution' rather than solution to waste problems.

Significant technological improvements in waste recycling, incineration and landfilling were introduced to achieve high environmental and economic efficiencies; however, with the systems view limited to the WM systems solely. Innovations were developed aiming at the systemic changes within the WM system only and have lacked in providing a long-term sustainable solution to the waste problems.

Recent systems-oriented progress to WM. Historically, organized municipal-wide WM resource-recovery operations driven by the market values of waste can be traced to the 18th century dust-yard systems in London (Velis et al., 2009). However, the resource recovery operations motivated, inter-alia, by the environmental implications with the discarded resources are recent. Especially, over the last two decades, waste-recycling facilities have been developed on an industrial scale in parallel with the introduction of various practical concepts throughout the product supply chain, for instance, eco-design, industrial symbiosis, pay as you throw (PAYT) and EPR principles (Lifset, 1993; OECD, 2006; USEPA, 2012).

Design for environment. 'Design for environment' is a term used as a synonym for several other names, such as ecodesign, sustainable design, green design, environmentally conscious design, life cycle design or life cycle engineering and also clean design. Although the phrasing may have different meanings, the concepts generally have the same objectives (Lagerstedt, 2003). The concept of design for environment has developed into different forms of design strategies to achieve specific environmental objectives - design for recycling, design for disassembly, design for remanufacturing, etc. (Gungor and Gupta, 1999). To encourage these design concepts, introduction of EPR as a policy was an important development in the area of resource management.

$E P R$. EPR recognizes the producer's role in reducing the impacts of their product throughout its entire life cycle, including WM or recovery at end-of-life. The central idea behind the EPR concept is to motivate the design for environment (Walls, 2006). EPR policies shift part, or all, of this responsibility from taxpayers, local authorities and conventional waste dealers to the producers (McKerlie et al., 2006). EPR has been implemented in many countries as a governmental policy regulation.

Industrial symbiosis and eco-industrial parks. Industrial symbiosis (Lehtoranta et al., 2011) and eco-industrial parks concepts rely on financial gain from symbiotic operation among different actors, such as groups of local companies and communities, with the exchange of energy, by-products and wastes (Ehrenfeld and Gertler, 1997; Roberts, 2004; Tudor et al., 2007).

\section{Current global WM system situation}

WM system development has strongly been linked with the contemporary drivers, goals and implications and has highly been dependent on social, political, economic and environmental issues at hand. Throughout the world, there are considerable variations in what are perceived as important drivers for WM. For example, in many developing countries, the strive for improved public health still remains a key driver for waste collection, while in most of Europe, public health is largely 'taken for granted' and is no longer a major driver (Wilson, 2007). Here, focus has moved to 'creative and efficient' management of resources. Recent studies (Scheinberg et al., 2010; Wilson et al., 2012b; Wilson et al., 2013) have reported significant improvements in the waste disposal technologies in many cities in the low- and middle-income countries. 
Highly active informal sectors for waste collection, in the low- and middle-income countries, make it more difficult to regulate and implement a new efficient and standardized waste treatment system (Wilson et al., 2012b). Indeed, there are twice as many people in the informal sector as in the formal (World Bank, 2005). This could be attributed to the reason that the traditional policies have neglected the role of the informal sector in WM. It has become increasingly evident that the preferred option is to integrate the informal sectors into formal WM planning to gain significant benefits from the mutual cooperation (Velis et al., 2012; Wilson et al., 2012b; Wilson et al., 2006). However, to integrate the informal recycling sector with the formal MSW system is a major challenge (Wilson et al., 2006). This integration needs to consider aspects such as: recognizing the contribution informal sectors make to WM system; the materials chain, along with the social situation; and organizational aspects required to underpin and enable the functioning of the interdependencies between various aspects (Velis et al., 2012).

In high-income countries, resources are being allocated on to collecting and analysing the waste related information (the European Union has to establish a framework for the production of community statistics on the generation, recovery and disposal of waste (European Union; 2002)), for example waste quantity and composition, by using computer-based simulation programs. However, such analyses are not yet common in low- and middleincome countries owing to a lack of financial resources; consequently, accessible information/data on waste is scarce. This poses several difficulties in planning and implementation of a sustainable WM system. Inadequate planning and other issues, such as landfill area scarcity, constrain municipalities to choose economically unsustainable WM practices, for example, prioritizing solid waste incineration over other waste disposal methods even when it is expensive (Bai and Sutanto, 2002; Jin et al., 2006).

Nonetheless, current international waste statistics fail to link the waste streams from extraction and production systems to the overall resource consumption and only municipal wastes streams get proper attention on social agendas. Therefore, current WM statistics do not reflect the real severity of the waste problems. There is a lack of data on how waste amounts are linked to consumption in a broad system. From a long term sustainability perspective, this presents a great challenge to resource/WM in society.

Finally, the role of legislations/regulations in the development of WM system cannot be ignored. For example, the European Union has banned landfilling of organics according to the recent EU landfill legislations. Lack of stringent legislation often leads to reliance on low technology solutions (Kumar et al., 2009). Governmental policies, in the area of WM, involve a range of legislations, directives and economic and regulatory instruments. Such instruments are important to foster an efficient management of resources and environmentally friendly treatment of wastes. However, Korhonen (2004) points out that environmental policy

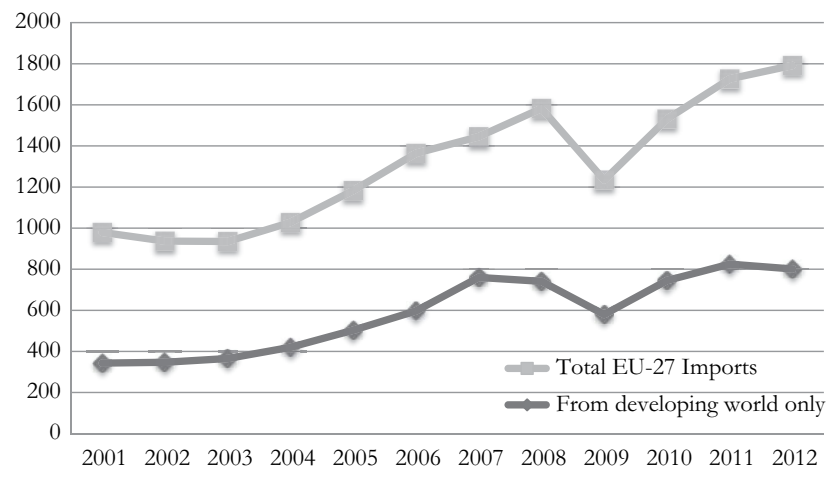

Figure 6. EU-27 total imports and the imports from the developing world only during the years 2001-2012. The values are in billions Euro worth of import (cost, insurance and freight).

Data source: EUROSTAT (2013)

and corporate environmental management can, at times, result in the creation of new problems while one seeks to solve old ones and the 'environmental bad' can be shifted or recycled from one part of the system to another. For instance, for the last few decades, increasing globalization is a result of companies shifting their production to low- and middle-income countries with cheap labour resources and relatively less stringent regulations. This increased international trade has 'de-linked' the production and consumption centres. Figure 6 shows the increasing trends in the imports by the 27 EU-member countries from the year 2001 to 2012, from the developing countries. (The total imports includes total billions Euro worth of food, drinks, tobacco; raw materials; minerals fuels, lubricants and related materials; chemicals and related materials; machinery and transport equipment; other manufactured goods; and commodities and transections not classified elsewhere in the Standard International Trade Classification. However, the imports from developing world includes food, drinks, tobacco; raw materials; minerals fuels, lubricants and related materials; and manufacturing goods (EUROSTAT, 2013).) This implies that the extraction/manufacturing wastes associated with the production of these imported goods/materials have been produced outside the EU-27 states. Hence, in this sense, the consuming nations, along with production, out-source a big part of wastes generation also (Bartelmus, 2003); they account only for the wastes due to the use and final disposal of a product. Therefore, to a great extent, the increasing industrial waste generation rates in low- and middle-income countries can be ascribed to the imports/consumption in the high-income importing countries.

The first glance at the global WM situation indicates that the WM problems are more serious in the developing countries, largely owing to the increasing waste generation rates and relatively under-developed infrastructure in these as compared with high-income countries. However, based on a high level of resource consumption in high-income countries stimulating the waste generation in the developing countries, one could argue that the overall seriousness of existing WM issues is with 
high-income countries and globally the resource/WM system is on a unsustainable trajectory. The historical forces and mechanisms that have driven the evolution of WM in high-income countries can provide insight about how to move forward in developing country contexts (Wilson, 2007). Many similarities exist between the historical WM development trajectories of industrialized countries and the current trajectories of developing countries (Marshall and Farahbakhsh, 2013). Thus, similar WM solutions could be proposed to solve WM problems in developing countries (here, developing countries refer to the low- and middle-income countries). However, there are several issues in context to developing countries that are different from the historical contexts of developed countries. Marshal and Farahbakhsh (2013) recognize that: rapid urbanization, soaring inequality and the struggle for economic growth; varying economic, cultural, socio-economic and political landscapes; governance, institutional and responsibility issues; and international influences, have created locally specific, technical and non-technical challenges of immense complexity, which presents a hurdle for WM in developing countries. In this situation, one could argue that implementation of the same solutions in rapidly growing economies would not be sufficient to solve the waste issues.

\section{Challenges to the global resource management system}

\section{Increasing global amounts of waste}

Increasing amounts of waste throughout world economies show an inextricable link between economic growth and waste amounts. In low- and middle-income countries, per capita waste generation rates are relatively low as compared with high income countries (Table 1 and Figure 1). However, they are increasing at a very fast rate. In high income countries, the per capita waste generation rates are already very high and are still increasing with economic growth. This is owing to the way resources are being 'consumed' in our society. A linear system of resource consumption is dominant mainly in all world economies. Various resources are transformed into different products in a predominantly global production system. The products are distributed to consumers on the global market and wastes fed into the WM system. Despite increasing recycling of materials, such as paper, metals and other valuable products, a predominantly linear production consumption chain is used.

Tremendous amounts of new wastes are entering into the waste streams. Consequently, even countries with a relatively developed infrastructure for WM face challenges to manage wastes sustainably for example, owing to (1) products that are not suited for recycling and (2) unsatisfactory waste sorting. Thus, it could be concluded that the overall WM is on an unsustainable trajectory still.

Sustainable resource management requires 'decoupling' resource consumption with the economic growth and a transition towards a circular model of resource consumption, where resource reuse and recycling are introduced through strategic planning throughout the production and consumption chain. This calls for an environmentally sound approach to WM that must go beyond the mere safe disposal, or recovery, of wastes that are generated and seek to address the root causes of the problem by attempting to change unsustainable patterns of production and consumption (UN, 1993).

\section{Increasing complexity of product composition and variety in the production and consumption systems}

The material resources undergo several transformations during their life-cycle stages (illustrated in Figure 7). High quality material resources produced during the extraction processes are used to make diverse products in the manufacturing systems by combining various material resources. Thus, the manufacturing systems act as 'resource diluting systems' in terms of the mass of a particular material resource. The products entering the consumption system leave the system in the form of various wastes, further result in dilution of resources in space and time. In addition, these transformations also result in changes in physical, chemical and biological properties of the material resources (GößlingReisemann, 2011). WM processes either 'concentrate' these resources through, for example recycling, or further 'dilute' them in one of their residues, such as through incineration or composting. From a resource scarcity perspective, the dilution of the many scarce material resources is not sustainable and these resources should be re-introduced into the socio-technical systems.

The manufacturing and consumption systems dilute the resources to a critically low level owing to the increasing product composition complexity. This leads to energy-intensive and hence costly recycling operations. This is the case for many materials where recycling is not economical or not possible technologically (Ayres, 1994; Ayres and Kneese, 1989). As long as the availability of energy is limited, the environmental cost of producing pure substances will prevent the recycling of materials beyond certain limits. Thus, the use of many nonrenewable resources is inherently unsustainable and attempts to close their loops will result in greater damage than good (Vesilind et al., 2007). Furthermore, recycling complex waste streams presents technological challenges and thus reduces their potential utility (Gößling-Reisemann, 2011; Rechberger and Brunner, 2001).

Over the last few decades, product diversity, in numbers and variety, has considerably been increased. Consequently, the waste materials discarded to the WM systems have also increased very much and likely to increase further. However, waste is categorized and sorted in limited numbers of fractions. Products with sophisticated material composition are often difficult to treat when they get discarded at the end of their useful phase. This presents challenges for the WM system to handle the wastes in a more sustainable way owing to poor sorting or complicated waste treatment processes (United Nations Environment Program, 2011). Thus, to foster efficient cycles of reuse, for 


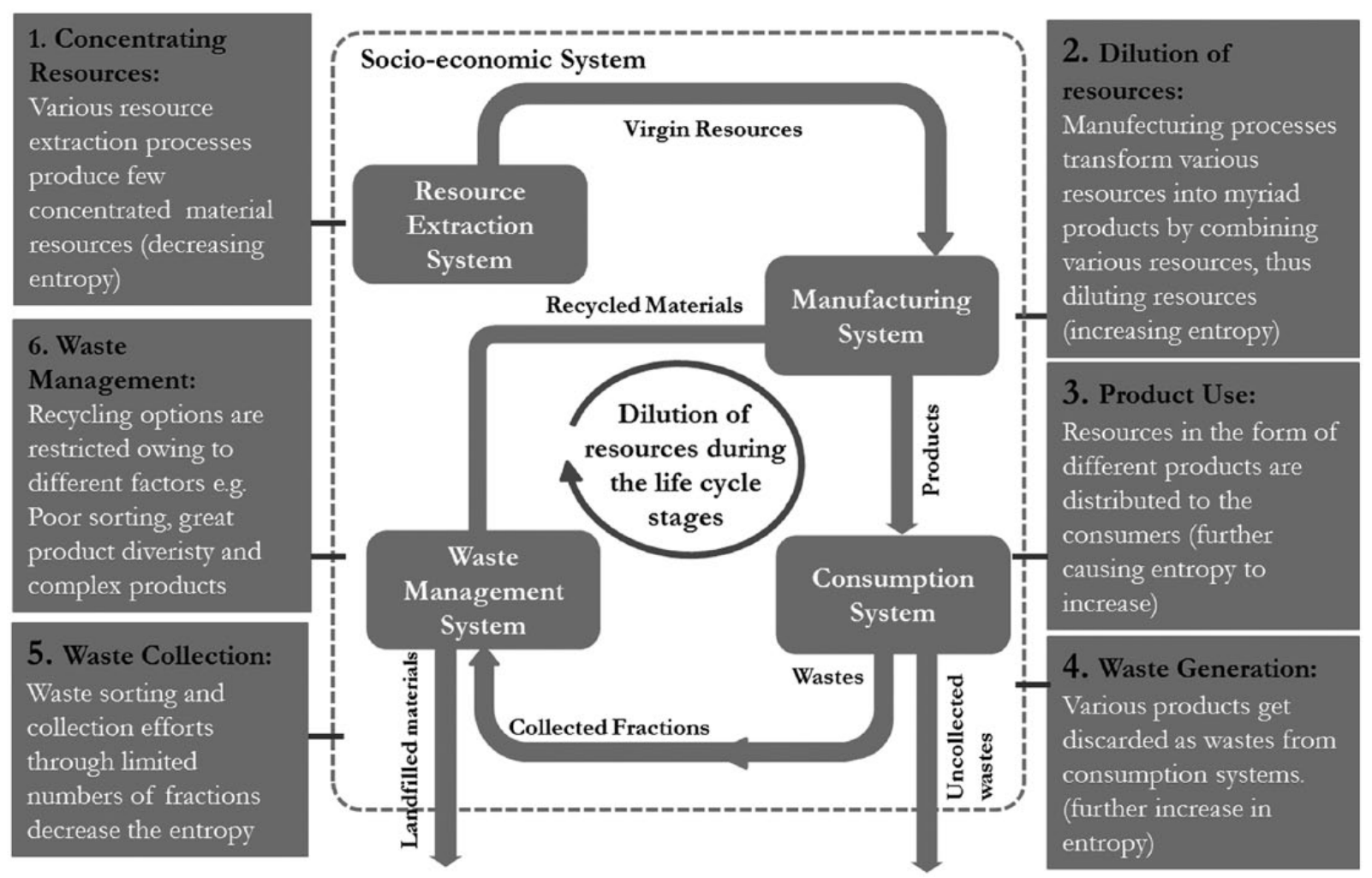

Figure 7. Illustration of resource materials with changing concentrations throughout the product's life cycle. The arrows indicate the material flows.

example remanufacturing and reassembly, it is important to maintain resource quality throughout the product chain. Consequently, it becomes of utmost importance to investigate the potential of a system to concentrate or dilute the resources.

\section{Lack of environmental awareness in society}

Environmental awareness in society plays an important role in sustainable consumption and disposal of resources. Participation of people in WM plays an important potential role in the overall operational efficiencies of any WM system. Poor waste-sorting behaviour among people directly hampers the recycling activities. Recyclable materials mixed with other kinds of wastes results in economically as well as environmentally inefficient recycling operations; consequently, making other treatment options, such as incineration or landfill, more attractive.

Studies have shown a strong concern among people for a clean environment and the belief that learning, information and awareness campaigns are important drivers to behaviour change (Mbeng et al., 2009). However, this does not necessarily translate into an increased participation in recycling or reuse initiatives. In high-income countries, people consider the disposal of waste as a significant environmental concern, but it is not an issue at the forefront of their minds. There is a lack of understanding about how resource issues are linked to global issues such as climate change, which is an issue that people are particularly aware of and concerned about. Consequently, there is often poor public participation in WM. The challenge is to successfully make the association between people's waste disposal behaviour and global concerns in the same way as they have linked climate change to car use and local flooding (MORI, 2002).

\section{Barriers to practical implementation and performance of various approaches to WM}

Many factors responsible for practical implementation and performance of various innovations in resource management have not been fully addressed yet. Consequently, often, policy interventions face failures during their implementation stages, for example owing to economic reasons or competition with existing approaches. Hence, the policy decisions fail to achieve the intended goals. For instance, the EPR concept has been introduced to strengthen product development processes, in particular, design for environment, in companies and to achieve much needed resource recovery (Walls, 2006). However, EPR systems do not fully internalize external costs of WM and therefore, reduce the incentives for waste prevention and green product design (Dubois, 2012). Studies have shown that the EPR is unlikely to drive eco-design at least in the short-run where; (1) product prices are inelastic and the effects of the EPR equal for all producers (Gottberg et al., 2006; Walls, 2006); and (2) in cases where such innovations harm companies economically, 'green technology loses and profitability wins' (Vesilind et al., 2007). 

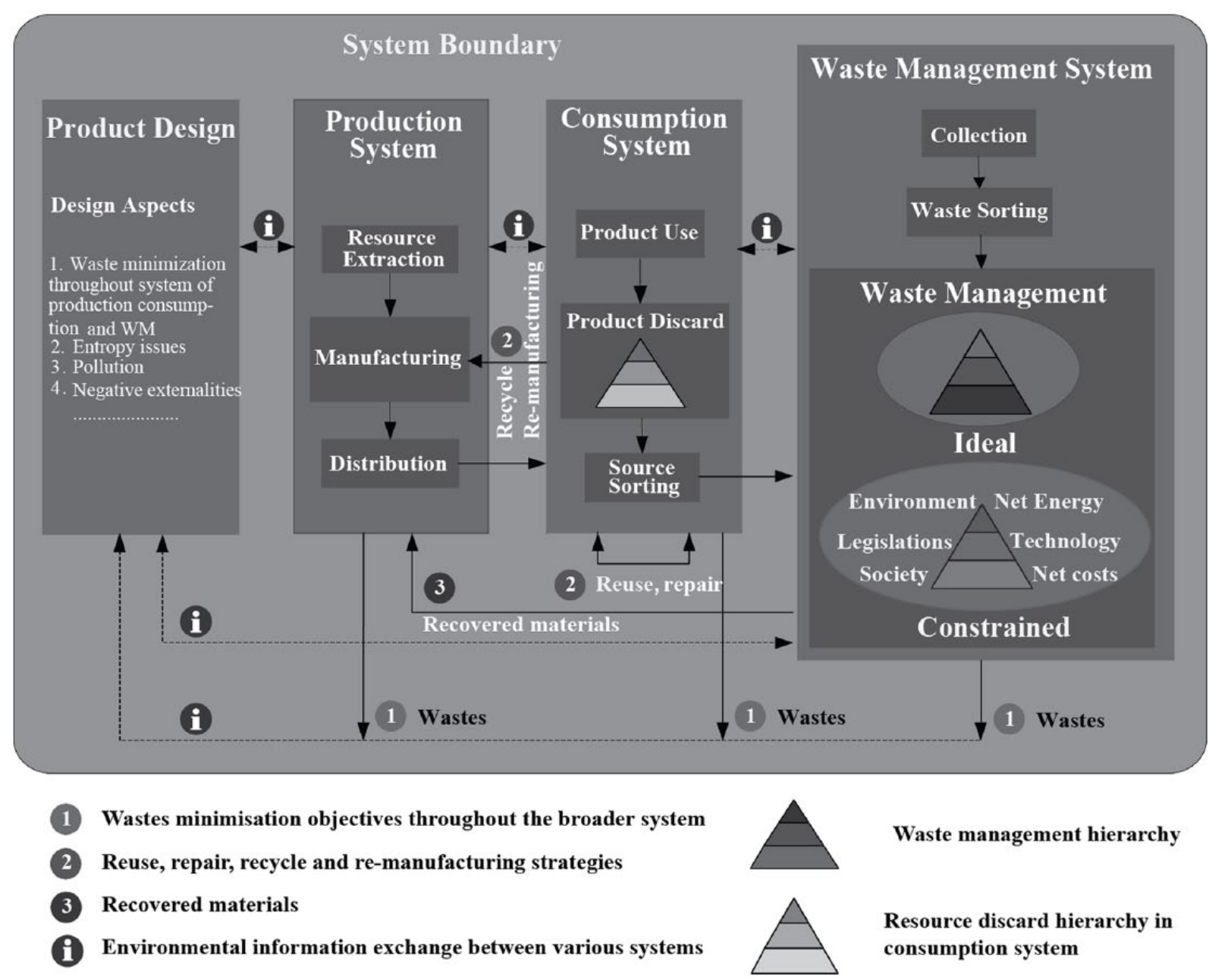

Waste management hierarchy

Resource discard hierarchy in consumption system

Figure 8. System interactions, processes and information flow in a broader design, production, consumption and WM system. The resource discard hierarchy in the consumption system refers to the hierarchical decisions of repair, reuse, remanufacturing and disposal of products/resources; whereas, the WM hierarchy refers to waste treatment options in the WM system. The product design system incorporates environmental aspects throughout the life cycle chain of a product along with other design aspects.

WM: waste management.

Sustainable development requires economy-wide adoption of the design concepts, such as eco-design and design for environment. The concept of EPR seems to blame the companies for some environmental problems, such as pollution, and at the same time fails to recognize the role of consumers who demand products with certain features that may cause the environmental problems (Wiesmeth and Häckl, 2011). Successful implementation and performance of such policy decisions requires considering various important variables, for example, economic incentives for companies and values and preferences of consumers. This demands: a careful observation of economic principles and technological developments during the design phase of incentivecompatible EPR policies (Wiesmeth and Häckl, 2011); effective implementation of the central idea of EPR by the transition of the global waste regimes still focusing on safe disposal towards a sustainable resource management throughout the product's life cycle chain (Wilts et al., 2011).

Resource dynamics is governed by a complex system that consists of various actors (consumers, producers, recyclers, etc.), institutions (manufacturing companies, mining industries, WM authorities, etc.) and aspects (social, economic, ecological and political). These actors/institutions engage themselves through various intricate interactions, generally with competing goals. These system interactions take place at various scales and levels, often having causes and impacts spanning multiple scales and levels. Indeed, in today's world, these interactions between production and consumption systems span the globe. Thus, addressing resource management issues requires a holistic understanding of the entire system of production and consumption by recognizing these multitudes of perspectives, cross-scale dynamics and actors' interactions at all the levels.

\section{Need for a broader systems approach to resource management}

We highlight the need for a broader systems approach to resource management based on a transition from a linear to circular economy. The approach suggests identifying various actors, sub- 
systems and causal mechanisms in the broader system of product design, production, consumption and WM (as illustrated in Figure 8). Creation of joint visions among various actors must be based on clearly defined objectives or coordination principles for the transition path toward the system goals. The approach insinuates developing a holistic view of the unified system of resource metabolism in the society with the following system's main objectives.

1. Reduction of residues/wastes/emissions throughout the system of production and consumption and WM.

2. Maintaining resource quality throughout the life cycle of the resource.

3. Establishing a worldwide shared vision among businesses and society.

From a sustainability perspective, the concept of WM should be broadened to the necessary control of gaseous, liquid and solid wastes in the environment, from all the activities - extraction, production and consumption. Resource management should aim towards a 'strong' conception of non-depletion of resources and zero-waste, rather than meeting the short-term goals. Implementation of a new innovative consumption model is needed, where reuse and repair, re-manufacturing and resource recovery are supported; and minimum resources enter and leave the socio-economic system (refer to Figure 5). This demands a better understanding of the whole system of production and consumption in order to develop strategies to minimize the residues/ wastes/emissions throughout the system of production, consumption and WM.

Poor sorting and increasing complexity of the product's composition limit sustainable resource recovery operations. To foster efficient cycles of reuse and resource recovery, maintaining the resource quality throughout the product chain becomes of utmost necessity. Thus, production and consumption systems should be analysed to quantify their potential to concentrate or dilute resources in order to develop strategies to maintain resource quality. An approach described by Rechberger and Brunner (2001), based on a comprehensive material flow analysis and Shannon's (1948) entropy function, could be employed here. The approach uses terms called relative statistical entropy and substance concentrating efficiency to quantify the potential of a system to concentrate or dilute resources (Rechberger and Brunner, 2001). Such studies can be helpful in addressing root causes for material losses throughout the system, and consequently, in planning and implementing strategies for better resource management.

In today's globalized economic operations, production systems utilise materials originating from all over the world, to produce products for customers, often international, and discarded products often sent to distant countries for recycling or disposal (Rotter, 2011). Thus, the objectives of sustainable resource management cannot be achieved without a worldwide shared vision among society and businesses.

The proposed approach requires a high degree of cooperation among a broad range of actors in the system. In order to engage various actors in the system towards this goal, a rationale based on their mutual interests must be established. Guiding broad system level interventions requires clearly defined systems' workable objectives, such as waste minimization, resource use efficiency and resource quality, as well as the roles and responsibilities of various actors and institutions. Various critical system dynamics (systems interactions, processes, stocks, stakeholders) should then be identified and strengthened in the broader system. This necessitates the establishment of improved life cycle-based databases reflecting the current status of the system in order to engage various actors in a debate for change. Therefore, before initiating any interventions, there is a need to improve the current database on resource use and wastes produced, and their environmental, social and economic impacts and how these aspects are interlinked in a broader system.

\section{Conclusion and discussions}

Our study concludes that the inextricable link between economic growth and resource consumption and wastes is a vital challenge throughout the world. The situation of WM in the middle- and low-income countries is very serious owing to the lack of infrastructure for WM and rapidly growing waste amounts. However (despite of relatively developed system for WM), the overall seriousness of WM issues is with high-income countries, owing to their high level of consumption. Despite significant progress in WM technologies, increasing complexity of product composition and variety in the production and consumption systems presents barriers to sustainable resource recovery operations. Lack of recognition of various cross-level and multi-scale system dynamics leads to the failure of different system interventions. Inadequate feedback between different systems of design, resource extraction, production and consumption shows a lack of a holistic approach to resource/WM. The study highlights that current statistics on waste under-represent the real severity of the waste problems and, from a global perspective, the overall WM system development is not on a sustainable trajectory.

A need for a broader systems approach to resource management has been highlighted. The approach suggests a pressureoriented approach rather than traditional state- or impact-oriented approach to resource management. As a first step towards a longterm physical resource management system, a need to broaden the systems boundary to design, production, consumption and WM is emphasized. The approach emphasizes the need for clearly defined systems' objectives that further requires shared worldviews on the dynamic link between social, economic, ecological and technical subsystems. Managing resources sustainably is a global challenge and it cannot be achieved without the active participation of society as a whole including producers, consumers and WM authorities at acting at various levels ranging from local to global. Such a resource management paradigm may require radical shifts in the current business structures, consumer behaviours, and governance regimes.

Realizing a global level initiative towards resource management could appear to be an unachievable task owing to the 
existing demographic, institutional, operational and economic differences at all the levels. However, there are examples of successful global system-level interventions, such as the Montreal Protocol (United Nations Environment Program, 2007), where different communities have shown a great level of cooperation to achieve a shared goal to prevent the ozone depletion. The institutions at global or regional levels, such as the United Nations and European Union, could provide a platform for global policy making for a sustainable resource management.

\section{Acknowledgements}

The authors would like to express their gratitude to Anna Björklund $(\mathrm{KTH})$, Per Jakobsson (KTH) and William Hogland (Linnaeus University) for their constructive comments. We are also immensely grateful to the anonymous reviewers for their suggestions to improve the paper.

\section{Declaration of conflicting interests}

The authors declare that there is no conflict of interest.

\section{Funding}

The authors would like to acknowledge Erasmus Mundus Action 2 projects - 'India4EU' and 'EU-Brazil STARTUP' - funded by European Commission for their financial support.

\section{References}

Anonymous (1991) Elaboration of a regional strategy on integrated waste management. In: Chair BF (ed.) Report From an ECE Task Force. United Nations.

Ayres UR (1994) Industrial metabolism: theory and policy. In: Ayres RU \& Simonis UE (eds) Industrial Metabolism; Restructuring for Sustainable Development. Tokyo: United Nations University Press, pp. 3-20.

Ayres UR and Kneese AV (1989) Externalities: Economics \& Thermodynamics. Economy \& Ecology: Towards Sustainable Development. Netherlands: Kluwer Academic Publishers.

Bai R and Sutanto M (2002) The practice and challenges of solid waste management in Singapore. Waste Management 22: 557-567.

Bartelmus P (2003) Dematerialization and capital maintenance: Two sides of the sustainability coin. Ecological Economics 46: 61-81.

Blanchard O (1992) Energy consumption and modes of industrialization: four developing countries. Energy Policy 20: 1174-1185.

Bylinsky G (1995) Manufacturing for reuse. Fortune 131: 102-103.

Carrillo-Hermosilla J, Del Río P and Könnölä T (2010) Diversity of ecoinnovations: reflections from selected case studies. Journal of Cleaner Production 18: 1073-1083.

Chalmin P and Gaillochet C (2009) An Abstract of World Waste Survey 2009. Available at: http://www.rebnews.com/pdfs/news/from_waste_to_ resource_report_veolia.pdf (accessed 12 December 2013).

Dubois M (2012) Extended producer responsibility for consumer waste: The gap between economic theory and implementation. Waste Management \& Research 30: 36-42.

EEA (2002) Case studies on waste minimisation practices in Europe. In: Jacobsen $\mathrm{H}$ and Kristoffersen $\mathrm{M}$ (eds) Copenhagen: European Environment Agency. Available at: http://www.eea.europa.eu/publications/topic_report_2002_2 (accessed 20 November 2013).

Ehrenfeld J and Gertler N (1997) Industrial ecology in practice: The evolution of interdependence at Kalundborg. Journal of Industrial Ecology 1: 67-79.

ESCAP (2000) The State of Environment. Chapter 8. ESCAP.

European Union (2002) Regulation (EC) No 2150/2002 of The European Parliament and of The Council of 25 November 2002. Waste Statistics. Available at: http://eur-lex.europa.eu/lexuriserv/lexuriserv.do?uri=oj:1:2002:332:0001:0036:en:pdf (accessed 12 May 2013).
European Union (2006) Decision No 1639/2006/EC of The European Parliament and of The Council of 24 October 2006. Establishing A Competitiveness And Innovation Framework Programme (2007 to 2013). Official Journal of the European Union. EU.

European Union (2008) European Union Framework Directive. Waste. European Union. Available at: http://eur-lex.europa.eu/lexuriserv/lexuriserv.do?uri=oj:1:2008:312:0003:0030:en:pdf (accessed 22 December 2011).

European Union (2012) Guidelines On Waste Prevention Programmes. EU. >Available at: http://ec.europa.eu/environment/waste/prevention/pdf/ waste\%20prevention_handbook.pdf (accessed 20 November 2013).

EUROSTAT (2013) Database. Available at: http://epp.eurostat.ec.europa. eu/portal/page/portal/statistics/search_database (accessed 20 September 2013).

Fell D, Cox J and Wilson DC (2010) Future waste growth, modelling and decoupling. Waste Management \& Research 28: 281-286.

Frosch RA and Gallopoulos N (1989) Strategies for manufacturing. Scientific American 261: 144-152.

Geng Y, Tsuyoshi F and Chen X (2010) Evaluation of innovative municipal solid waste management through urban symbiosis: A case study of Kawasaki. Journal of Cleaner Production 18: 993-1000.

Gerbens-Leenes PW, Nonhebel S and Krol MS (2010) Food consumption patterns and economic growth. Increasing affluence and the use of natural resources. Appetite 55: 597-608.

Gottberg A, Longhurst PJ and Cook MB (2010) Exploring the potential of product service systems to achieve household waste prevention on new housing developments in the UK. Waste Management \& Research 28: $228-235$.

Gottberg A, Morris J, Pollard S, Mark-Herbert C and Cook M (2006) Producer responsibility, waste minimisation and the WEEE Directive: Case studies in eco-design from the European lighting sector. Science of the Total Environment 359: 38-56.

Gungor A and Gupta SM (1999) Issues in environmentally conscious manufacturing and product recovery: A survey. Computers \& Amp; Industrial Engineering 36: 811-853.

Gößling-Reisemann S (2011) Entropy production and resource consumption in life-cycle assessments. In: Bakshi BR, Gutowski TG and Sekulic DP (eds) Thermodynamics and the Destruction of Resources. Cambridge: Cambridge University Press.

Jin J, Wang Z and Ran S (2006) Solid waste management in Macao: Practices and challenges. Waste Management 26: 1045-1051.

Korhonen J (2004) Industrial ecology in the strategic sustainable development model: Strategic applications of industrial ecology. Journal of Cleaner Production 12: 809-823.

Kronenberg J and Winkler R (2009) Wasted waste: An evolutionary perspective on industrial by-products. Ecological Economics 68: 3026-3033.

Kumar S, Bhattacharyya JK, Vaidya AN, Chakrabarti T, Devotta S and Akolkar AB (2009) Assessment of the status of municipal solid waste management in metro cities, state capitals, Class I cities, and Class II towns in India: An insight. Waste Management 29: 883-895.

Lagerstedt J (2003) Functional and environmental factors in early phases of product development - eco functional matrix. Phd Dissertation, Kth Royal Institute of Technology, Sweden.

Lehtoranta S, Nissinen A, Mattila T and Melanen M (2011) Industrial symbiosis and the policy instruments of sustainable consumption and production. Journal of Cleaner Production 19: 1865-1875.

Lifset R (1993) Take it back: Extended producer responsibility as a form of incentive-based policy. Journal of Resource Management and Technology 21: 163-175.

Marshall RE and Farahbakhsh K (2013) Systems approaches to integrated solid waste management in developing countries. Waste Management 33: 988-1003.

Mbeng L, Probert J, Phillips P and Fairweather R (2009) Assessing public attitudes and behaviour to household waste management in Cameroon to drive strategy development: A Q methodological approach. Sustainability 1: $556-572$.

McKerlie K, Knight N and Thorpe B (2006) Advancing extended producer responsibility in Canada. Journal of Cleaner Production 14: 616-628.

MORI (2002) Public Attitudes Towards Recycling and Waste Management. MORI Social Research Institute. 
Munir SM, Abdul Manan Z and Wan Alwi SR (2012) Holistic carbon planning for industrial parks: A waste-to-resources process integration approach. Journal of Cleaner Production 33: 74-85.

Nakaiwa M, Kawasaki S, Naka Y, Baba K and Takamatsu T (1986) Design of electric power generation systems using waste heat energy. Energy Conversion and Management 26: 277-281.

OECD (1998) Waste Minimisation in OECD Member Countries. OECD. Available at: http://search.oecd.org/officialdocuments/displaydocume ntpdf/?doclanguage $=$ en $\&$ cote $=$ env/epoc/ppc(97)15/rev2 (accessed 18 August 2013).

OECD (2000) Database on environment [Online]. OECD. Available at: http://www.oecd.org (accessed 10 August 2011).

OECD (2006) EPR policies and product design: Economic theory and selected case studies [Online]. OECD. Available at: http://www.oecd. org/document/19/0,3746,en_2649_34281_35158227_1_1_1_1,00.html (accessed 1 May 2012).

Rechberger H and Brunner PH (2001) A new, entropy based method to support waste and resource management decisions. Environmental Science \& Technology 36: 809-816.

Roberts BH (2004) The application of industrial ecology principles and planning guidelines for the development of eco-industrial parks: An Australian case study. Journal of Cleaner Production 12: 997-1010.

Rotter VS (2011) Waste management and producer responsibility: A score behind - a new ahead. Waste Management \& Research 29: 889-890.

Rylander H (1985) Waste management in Sweden. A national report. Waste Management \& Research 3: 81-88.

Scheinberg A, Wilson DC and Rodic L (2010) Solid Waste Management in the World's Cities: Water and Sanitation in the World's Cities 2010. London, UK: Earthscan For Un-Habitat.

Seadon JK (2010) Sustainable waste management systems. Journal of Cleaner Production 18: 1639-1651.

Shannon CE (1948) A mathematical theory of communication. The Bell System Technical Journal 27: 379-423, 623-656.

Sharp V, Giorgi S and Wilson DC (2010) Methods to monitor and evaluate household waste prevention. Waste Management \& Research 28: 269-280.

Sternlicht B (1982) Waste energy recovery: An excellent investment opportunity. Energy Conversion and Management 22: 361-373.

Stiles SC (1996) A multi-media, integrated approach to environmental compliance and enforcement. Industry and Environment 19: 12-14.

Tudor T, Adam E and Bates M (2007) Drivers and limitations for the successful development and functioning of EIPS (eco-industrial parks): A literature review. Ecological Economics 61: 199-207.

UN (1993) Report of the United Nations Conference on Environment and Development. New York: United Nations.

UNEP (2011) Towards a Green Economy: Pathways to Sustainable Development and Poverty Eradication, Part II: Investing in Energy and Resource Efficiency.

UNFCCC (2005) Key GHG Data. Greenhouse Gas Emissions Data for 1990-2003 Submitted to the United Nations Framework Convention on Climate Change. UNFCCC Secretariat, Bonn, Germany. Available at: http://unfccc.int/resource/docs/publications/key_ghg.pdf (accessed 28 January 2013).

United Nations Environment Program (2007) Montreal protocol on substances that deplete the ozone layer 2007: A success in the making.
The United Nations Ozone Secretariat, United Nations Environment Programme.

USEPA (2012) Resource conservation and tools [Online]. USEPA. Available at: http://www.epa.gov/osw/conserve/tools/payt/ (Accessed 1 May 2012).

Velis CA, Wilson DC and Cheeseman CR (2009) 19th century London dustyards: a case study in closed-loop resource efficiency. Waste Management 29: 1282-1290.

Velis CA, Wilson DC, Rocca O, Smith SR, Mavropoulos A and Cheeseman CR (2012) An analytical framework and tool ('intera') for integrating the informal recycling sector in waste and resource management systems in developing countries. Waste Management \& Research 30: 43-66.

Vesilind P, Heine L and Hamill S (2007) Kermit's lament: it's not easy being green. Journal of Professional Issues in Engineering Education and Practice 133: 285-290.

Walls MA (2006) Extended producer responsibility and product design: Economic theory and selected case studies. In: Resources for the Future. Washington, D.C.: OECD.

Wenheng W and Shuwen N (2008) Impact study on human activity to the resource-environment based on the consumption level difference of China's Provinces or autonomous regions. China Population, Resources and Environment 18: 121-127.

Wiesmeth H and Häckl D (2011) How to successfully implement extended producer responsibility: Considerations from an economic point of view. Waste Management \& Research 29: 891-901.

Wilson DC (2007) Development drivers for waste management. Waste Management \& Research 25: 198-207.

Wilson DC, Parker D, Cox J, et al. (2012a) Business waste prevention: A review of the evidence. Waste Management \& Research 30: 17-28.

Wilson DC, Rodic L, Scheinberg A, Velis CA and Alabaster G (2012b) Comparative analysis of solid waste management in 20 cities. Waste Management \& Research 30: 237-254.

Wilson DC, Velis C and Cheeseman C (2006) Role of informal sector recycling in waste management in developing countries. Habitat International 30: 797-808.

Wilson DC, Velis CA and Rodic L (2013) Integrated sustainable waste management in developing countries. In: Proceedings of the Ice - Waste and Resource Management, 166: 52-68. Available at: http://www.icevirtuallibrary.com/content/article/10.1680/warm.12.00005 (accessed 19 September 2013).

Wilts H (2012) National waste prevention programs: Indicators on progress and barriers. Waste Management \& Research 30: 29-35.

Wilts H, Bringezu S, Bleischwitz R, Lucas R and Wittmer D (2011) Challenges of metal recycling and an international covenant as possible instrument of a globally extended producer responsibility. Waste Management \& Research 29: 902-910.

World Bank (2005) Waste management in China: Issues and recommendations. Urban Development Working Papers No. 9, East Asia Infrastructure Department. The World Bank.

World Bank (2012) What a waste: A global review of solid waste management. Urban Development \& Local Government Unit. Washington, DC: The World Bank. Available at: http://go.worldbank.org/BCQEP0TMO0. (accessed 24 November 2012).

Zorpas AA and Lasaridi K (2013) Measuring waste prevention. Waste Management 33: 1047-1056. 